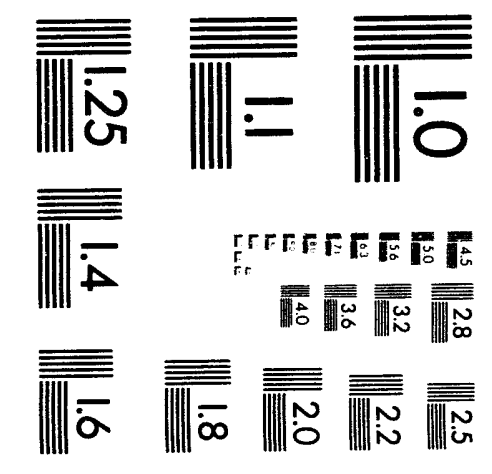



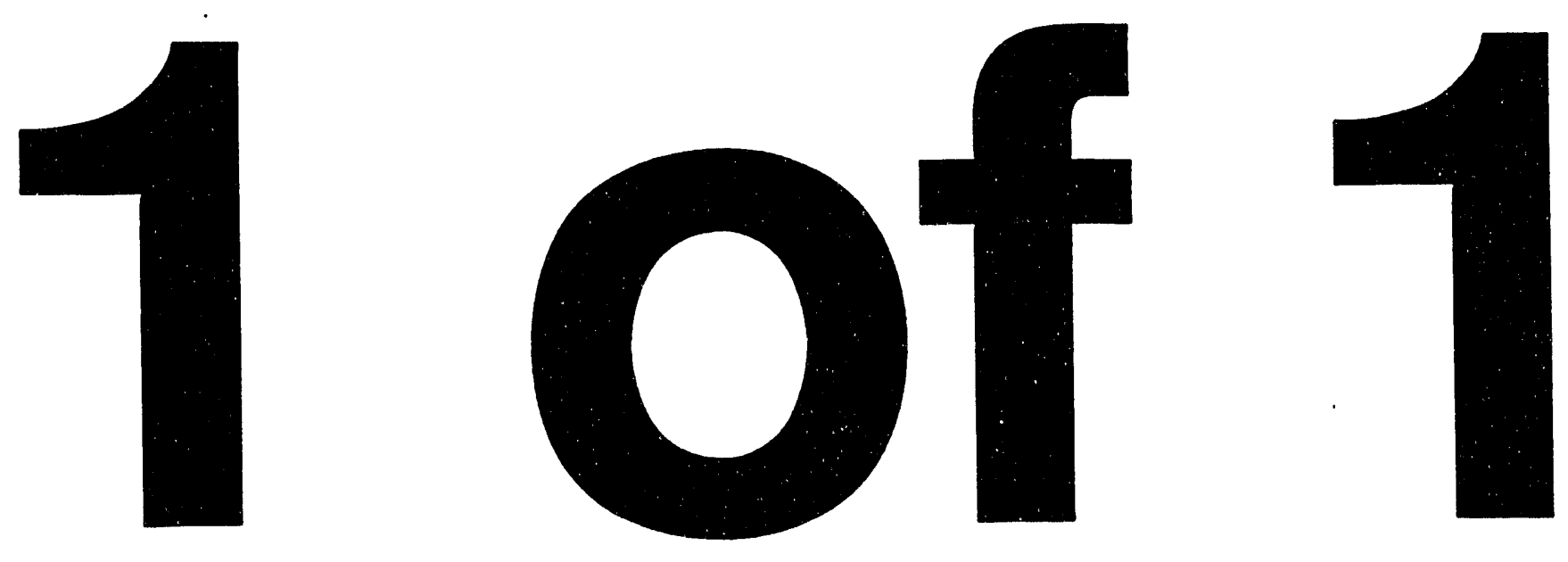


\section{Security Plan for the Automated Transportation Management System}

Prepared for the U.S. Department of Energy

Office of Environmental Restoration and Waste Management

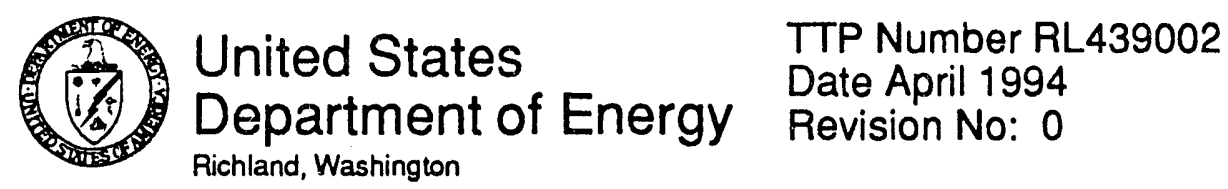

Approved for Public Release 


\section{LEGAL DISCLAIMER}

This report was prepared as an account of work sponsored by an agency of the United States Government. Neither the United States Government nor any agency thereof, nor any of their employees, nor any of their contractors, subcontractors or their employees, makes any warranty, express or implied, or assumes any legal liability or responsibility for the accuracy, completeness, or any third party's use or the results of such use of any information, apparatus, product, or process disclosed, or represents that its use would not infringe privately owned rights. Reference herein to any specific commercial product, process, or service by trade name, trademark, manufacturer, or otherwise, does not necessarily constitute or imply its endorsement, recommendation, or favoring by the United States Government or any agency thereof or its contractors or subcontractors. The views and opinions of authors expressed herein do not necessarily state or reflect those of the United States Government or any agency thereof.

This report has been reproduced from the best available copy. Available in paper copy and microfiche.

Available to the U.S. Department of Energy and its contractors from

Office of Scientific and Technical Information

P.0. Box 62

Oak Ridge, TN 37831

(615) 576-8401

Available to the public from the U.S. Department of Commerce National Technical Information Service

5285 Port Royal Road

Springfield, VA 22161

(703) 487.4650

Printed in the Unitod States of America

DISCLM-1.CHP (1.91) 
I. INTRODUCTION . . . . . . . . . . . . . . . . . . . 1

A. Identification and Location of the ADP System $\ldots \ldots \ldots \ldots \ldots \ldots \ldots$

B. Íientification of Computer Security Officers $\ldots \ldots \ldots \ldots \ldots \ldots \ldots \ldots$

C. Narrative Description of the ADP System ................. 2

D. Local Statement of Threat ...................... 2

E. Description of the ADP Computer Security Environment $\ldots \ldots \ldots \ldots \ldots 3$

F. Basis for Certification .........................

II. SECURTTY CONTROLS $\ldots \ldots \ldots \ldots \ldots \ldots \ldots \ldots \ldots \ldots \ldots \ldots$

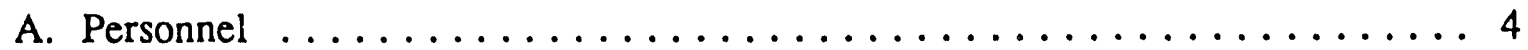

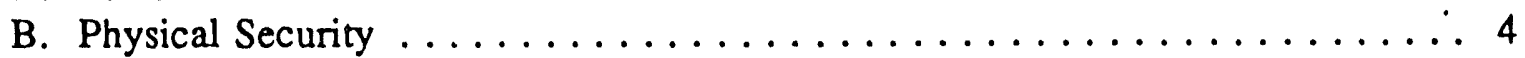

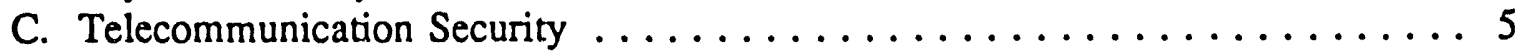

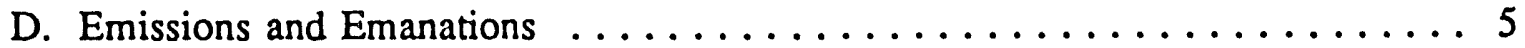

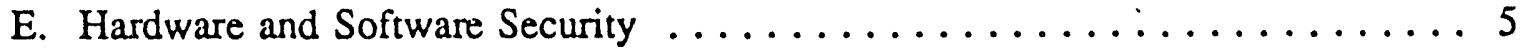

F. Administrative (Procedural) Security $\ldots \ldots \ldots \ldots \ldots \ldots \ldots \ldots \ldots$

G. Risk Assessment $\ldots \ldots \ldots \ldots \ldots \ldots \ldots \ldots \ldots \ldots \ldots$

H. Computer Security Incident Reporting $\ldots \ldots \ldots \ldots \ldots \ldots \ldots \ldots$

I. Contingency Plans and Recovery Procedures ................ 9

\section{APPENDICES}

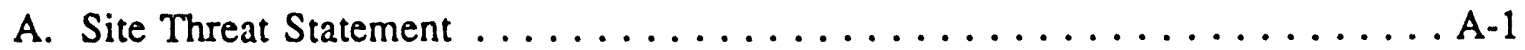

B. ATMS User Certification $\ldots \ldots \ldots \ldots \ldots \ldots \ldots \ldots \ldots \ldots \ldots \ldots \ldots \ldots \ldots \ldots \ldots$

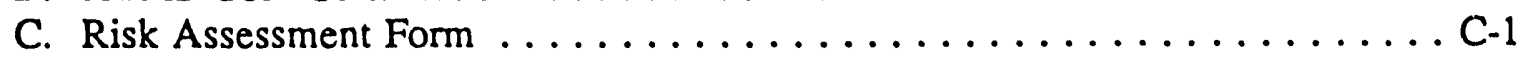

D. Computer Security Incident Report $\ldots \ldots \ldots \ldots \ldots \ldots \ldots \ldots \ldots \ldots \ldots \ldots \ldots$ 


\section{AUTOMATED TRANSPORTATION MANAGEMENT SYSTEM SECURITY PLAN}

\section{INTRODUCTION}

The Automated Transportation Management System (ATMS) is an unclassified, nonsensitive system consisting of hardware and software designed to facilitate the shipment of goods for the U. S. Department of Energy (DOE). The system is secured against waste, fraud, abuse, misuse, and programming errors through a series of security measures that are discussed in detail in this document.

A. Identification and Location of the ADP System

ATMS is a distributed system, with client personal computers residing at DOE facilities nationwide, UNIX server engineering workstations residing at selected regional locations, and a host VAX 6310 residing at Oak Ridge National Laboratory (ORNL) in Oak Ridge, Tennessee. US DOE is responsible for ATMS, with programmatic responsibility residing in the Transportation Management Division at DOE headquarters.

ATMS will initially consist of four software components: the Logistics Module, the Hazardous Materials (HAZMAT) Module, the Central Module, and the Packaging Management Tracking System (PMTS). The Logistics component will be installed at DOE transportation facilities nationwide; the HAZMAT and PMTS components will be installed on regional minicomputers; and the Central Module will be installed only on the VAX 6310 at ORNL.

B. Identification of Computer Security Officers

A Computer Protection Program Coordinator (CPPC) from DOE headquarters will be designated to serve as the focal point in coordinating security activities between the individual DOE sites and the Office of ADP Management.

A Computer Protection Program Manager (CPPM) will be appointed at the contractor/developer level to serve as the first level manager of all security activities. Two alternate CPPMs will be designated to assist the CPPM in security activities.

The Traffic Manager at each DOE facility will assume responsibility for ensuring the security of local workstations, and reporting any breaches in security to the CPPM. 


\section{Narrative Description of ADP System}

The ATMS system is initially composed of four software components: the Logistics Module, the HAZMAT Module, the Central Module, and the Packaging Management Tracking System. These components are briefly described in the following paragraphs.

Logistics Module: This component is designed to facilitate the day-today tasks of the transportation department at all DOE sites nationwide. It assists the shipper in shipment preparation, paperwork preparation, rating, routing, prepayment auditing, and various other tasks that make up the shipper's daily routine.

HAZMAT Module: This component contains all applicable federal regulations, DOE orders, IATA regulations, emergency response information, and other data necessary to prepare hazardous materials and hazardous waste shipments. This information is located regionally to control the currency and accuracy of the module, to assure that each site is using the same version of the regulations, and to eliminate the need for the local facilities to maintain the regulations.

Central Module: This component will provide access to commonlyused data, such as nationwide carrier rates and tenders, and carrier performance. Additionally, this module will consolidate all DOE shipments nationwide in order to conduct DOE-wide analyses of shipping patterns, to track DOE-wide hazardous shipments, and to perform corporate-level decision making.

PMTS Module: This component will provide relevant location, status, documentation and maintenance schedules for packagings of interest to DOE and its contractors.

Access to these modules will be controlled through the operating system software, which verifies authorized user IDs and passwords, and application based algorithms which verify user IDs, passwords, and access privileges.

\section{Local Statement of Threat}

All ATMS threats are covered by the Site Statement of Threat, included as Appendix A. This threat statement is based upon the U. S. DOE Statement of Generic Threats against Classified Computing Resources, dated October 1987. 
E. Description of the ADP Computer Security Environment

1. Protection Index

The ATMS system and its components are both unclassified and non-sensitive. Therefore, the protection index is not applicable.

2. Classification of Data

All ATMS data is unclassified and non-sensitive.

3. System Architecture

The Logistics module will operate on client microcomputers residing at DOE facilities nationwide. The HAZMAT and PMTS modules will operate on UNIX server workstations which will reside at selected regional sites. The Central module will operate on a host VAX 6310 which resides at ORNL.

4. System Components

ATMS consists of UNLX and DOS operating systems, the Oracle relational database management system, and custom-developed Logistics, HAZMAT, Central and PMTS modules.

5. Procedures for review and approval of modifications

The CPPM is responsible for reviewing proposed changes for possible effects on security. Hardware and software modifications to ATMS, as well as changes to the physical facility, are reviewed by the CPPM to determine if the system security requirements remain effective. If change is warranted, the ATMS Security Plan is updated.

6. Environment of the facility

The ORNL facility which houses the VAX 6310 is a secured building which requires identification badges for entrance. The computer room itself is a locked room which may only be unlocked by approved personnel.

\section{F. Basis for Certification}

A formal ATMS Test Plan will be released and implemented prior to formal release. The security features of the system, such as 
user IDs and passwords will be tested to verify proper functionality. The level of authorization will also be verified to ensure that only preapproved users can approve payment of freight bills, and perform other controlled activities.

\section{SECURITY CONTROLS}

\section{A. Personnel}

ATMS hardware can be used only by authorized users for official purposes. The regional minicomputers and the VAX 6310 at ORNL are located in controlled-access buildings where unauthorized visitors must be escorted. Physical removal of hardware and/or software is not authorized without written approval issued by the CPPM.

Personnel are either approved for access to the computers or are required to be under continuous escort. If it is necessary for unapproved hardware/software maintenance or other personnel to access the computers, an approved escort accompanies the individual. The unapproved employee must sign a guest log.

The use of ATMS software is authorized only for personnel who have been properly trained in assigned work and applications. In addition, all administrative support personnel, operators and programmers attend computer security awareness training conducted by the CPPM.

If an employee becomes a suspected security risk, his or her access to the computer systems is evaluated by his/her supervisor and the CPPM.

Upon termination of employment, former employees are not authorized access to the ATMS hardware or software. The terminated employee's user ID and password are removed from the ATMS software application's authorized access list. Also, the operator console user ID and password are changed immediately.

\section{B. Physical Security}

ADP security is necessary for the protection of data against theft, modification, destruction, and unauthorized access by unapproved personnel without authorization and a demonstrated "need-to-know." Protection is afforded to the single and multi-user systems, their operating software, application programs, and data commensurate with the "unclassified, nonsensitive" classification level. 
The following procedures are established to provide access to properly authorized personnel having a legitimate and documented "need-to-know" while denying access to all others. All operators and programmers have been approved for access to the information by the CPPM.

Building Access. An employee is stationed at the door of the buildings which house the VAX 6310. In addition to displaying a badge, approved personnel must sign a log upon entering and exiting the building. Only approved personnel are allowed access to the computer rooms. Regional machines will be located at secure onsite facilities.

Computer Room Access. The VAX 6310 computer resides in a locked computer room. Only approved personnel have the authority to lock and unlock the computer rooms. Once unlocked, the room is attended at all times by approved personnel.

\section{Telecommunication Security}

Modem phone numbers and other access is strictly controlled by the CPPM. Only approved users have access to the system.

\section{Emissions and Emanations}

Because ATMS is not considered a classified system, no special safeguards will be taken against emissions and emanations from the system. Each ATMS user is individually responsible for ensuring that persons viewing the system are not considered a threat.

\section{E. Hardware and Software Security}

All software is tested for known viruses prior to installation. Virus scanning applications are installed on all microcomputers, workstations, and the VAX 6310.

\section{F. Administrative (Procedural) Security}

\section{Physical Access}

The building which houses the VAX 6310 is secured by an employee, who verifies that each person is authorized to enter the building by checking identification badges. Further, the specific room which houses the VAX 6310 is locked, and only approved personnel have the authority to lock and unlock the computer room. Once unlocked, the room is attended at all times by approved personnel. The 
UNIX server engineering workstations will reside in controlled-access buildings at regional locations.

\section{Shared Microcomputers}

Microcomputers which reside in the traffic departments at DOE facilities nationwide will be equipped with several ATMS modules. These microcomputers may often be used by more than one person on any given day. Each ATMS user is responsible for ensuring the protection of ATMS data by logging out of ATMS each time he leaves the workstation. This is especially important because some users may have higher privileges than others. Overrides and freight payment authorizations are tracked by the ATMS software, and records of the user which performed these functions are kept within the ATMS software.

\section{Destruction of ADP Media}

Since ATMS data is unclassified and non-sensitive, no special steps will be taken in the destruction of ADP media.

\section{ADP Security Training}

Security training is required for all approved personnel. Training is arranged by the Traffic Manager and the CPPM at each local facility for authorized shipping personnel.

All authorized personnel will attend computer security awareness training before accessing ATMS. A training completion certificate is awarded upon completion of the training, and is retained by the CPPM, with a copy forwarded to each employee's training file.

In addition, each user, programmer, and operator must read and sign the ATMS User Certification, included as Appendix B. This form is read, initialed, and dated annually. The signed form is retained by the CPPM, with a copy forwarded to each employee's training file.

\section{Media Marking and Inventory}

Each user maintains responsibility for ensuring that output is properly marked. The user maintains responsibility for ensuring that output to be destroyed is destroyed appropriately. 
Removable disks and magnetic tapes must be properly marked and shall be serialized and logged for inventory purposes. The CPPM shall perform an annual inventory of removable disks and magnetic tapes.

\section{Media Sanitization}

ATMS information shall be properly deleted from magnetic media (tapes, disks, etc.). Because ATMS infonnation is neither sensitive nor classified, no special degaussing techniques will be employed.

7. Review of ADP System Files

Periodic reviews of ATMS files will be conducted by the CPPM. Procedures will be established prior to system implementation.

\section{Managing User IDs}

Software controls are included in the ATMS application software to monitor user identification and authentication. User IDs and passwords are issued to approved users, operators, and developers. There are three permission levels. The "user" permission level includes the least amount of access. Users may access those features that are necessary for the "use" of the ATMS software in daily transportation activities. The "privileged" permission level grants authority to approve payment of freight bills. The "operator/developer" permission level includes sufficient access rights to properly maintain the ATMS software. Within each permission level, there are "roles" assigned which provide access to specific privileges at the table level.

9. Privileged users of the system

Certain users of the IIS module will be granted higher privileges in order to approve payment of freight bills and to perform any other functions which need to be carefully controlled. Authorization for such privileges is established by formal authorization forms signed by the user and the traffic manager, and approved by the CPPM.

\section{Accountability Controls}

Audit trails will be generated by the ATMS software. A VAX 6310 login/logout report will be printed monthly. The regional workstations provide daily reporting of attempted logins. These reports 
are retained for a period of two years. Software controls will be included in the ATMS software to check data integrity and to validate user access.

\section{Media Protection Procedures}

Media such as diskettes, magnetic tape, cassettes, etc. will be checked for viruses prior to their use in ATMS. Once the media devices contain ATMS information, they must be properly secured in a locked facility or storage device when not in use.

\section{Temporary Operation during Updates}

Updates of microcomputer-based modules will be distributed to DÓE facilities nationwide. When updates are issued, the technical project manager is responsible for ensuring the timely installation of the IIS updates.

Updates of the regional workstation modules will be distributed to regional facilities which will be designated at a later date. The technical project manager is responsible for ensuring the timely installation of the updates. Updates will be performed during regularly scheduled block times.

Updates of the Central module will be installed on the VAX 6310 during non-working hours.

For all modules of ATMS, the prior version will be used until the updates are installed and properly functioning.

\section{Remote Diagnostic Services}

Not applicable to ATMS.

\section{G. Risk Assessment}

A risk assessment of ATMS will be conducted by completing a Risk Assessment Form, which is included as Appendix C. The CPPM reviews the risk assessment, and determines if additional risks apply to the specific systems. A risk assessment will be conducted at the following intervals:

- Prior to operational use of the system

- Whenever there is a significant change to the system 
- At periodic time intervals established by the CPPM commensurate with the sensitivity of the data, but not to exceed every five years if no risk assessment has been performed during that period.

\section{H. Computer Security Incident Reporting}

Incident reporting is accomplished by following the procedures provided below, and by completing the Computer Security Incident Report, which is included as Appendix D.

1. When an ATMS user suspects that a computer related incident has occurred, the user shall immediately notify the CPPM.

2. The CPPM conducts the investigation of the incident.

3. The CPPM follows up the investigation by providing additional training and/or information to personnel as needed to help prevent a recurrence of the incident.

4. The CPPM shall determine any additional corrective actions required and determines if a security incident is to be assigned (and to whom) based on the results of the investigation. The CPPM is required to report each incident to the cognizant DOE CPPC.

It is critical that this procedure be invoked in a timely manner and without delay. This is necessary to limit any potential problems and to allow for proper reporting response to $\mathrm{DOE}$.

\section{Contingency Plans and Recovery Procedures}

The CPPM will evaluate each component of ATMS to determine if it is a mission-essential system (i.e., one that is essential to the mission of the project). The designation of a component as mission-essential is used extremely sparingly and reflects a need to have the particular application available at any given time regardless of the threat.

The ATMS hardware is considered non-mission-essential. The Logistics component of ATMS will be installed on each DOE site's designated personal computers. In the event of a computer failure, the software can be accessed through another personal computer, or can be restored from diskette. The HAZMAT and PMTS modules will be installed on several regional minicomputers, and can also be restored from backup media in the event of a 
computer failure. In addition, the other regional systems act as back ups. The Central module will be installed on the VAX 6310, with a back up copy available in the event of a computer failure. 


\section{APPENDIX A \\ SITE THREAT STATEMENT}

The Site Generic Statement of Threat Against Computing Resources contained herein is based on the U. S. Department of Energy Statement of Generic Threat against Classified Computing Resources, dated October 1987.

\section{INTRODUCTION}

This document is intended to provide generic threat information which must be addressed in the preparation of ADP Security Plans established to guard the computing resources and information against compromise, destruction, misuse, loss, unauthorized disclosure, or denied authorized access, either accidental or malicious.

\section{GENERAL}

The threats identified in this document are described in a format which addresses each category in a singular fashion, recognizing that there are overlapping characteristics (e.g., water damage from fire fighting, etc.).

In the consideration of responses to certain threat scenarios, it is necessary to address the need for the emergency evacuation of personnel and the effects of such an evacuation. Protection of human health and safety must be given priority over the orderly protection of resources and information.

\section{HUMAN THREATS}

\section{General}

Consideration should be given to the length of time in which the individual is willing to take action (i.e., exposure) and the risk the individual is willing to take (i.e., loss of employment, incarceration).

The threats generated by human activities can be divided into two general categories. The first category is the result of unintentional actions (i.e., there is no premeditated intent to inflict damage). The second is the result of intentional actions (i.e., there is full intent to inflict damage). Examples of the results these actions incur are as follows:

- $\quad$ Erasing files

- $\quad$ Reading or stealing printed output

- Reading, copying, or altering stored data

- Improperly modifying or installing unauthorized software, firmware, or hardware 
- Incorrectly operating the system

- Causing a system crash or other unauthorized event

- Observing or stealing the passwords of others

- Damaging equipment or storage devices.

These examples are not intended to be complete or all-encompassing. Whether it is the result of benign or malevolent intent, a single action can still create the same basic threat to computer resources or information.

The following list categorizes human threats. There is considerable overlap and similarity between various categories. Protection against one threat category may be more than adequate to cover one or more of the others.

\section{Insider}

\section{General}

The threats posed by the insider range from the curious browser to the intentionally malicious. The results of an innocent access to the system are usually limited to compromised exposure of the information and possibly the unintentional alteration or destruction of data. The results of access by an employee (authorized or not) with malicious intent, however, present the full range of damage possibilities to the secure system. The rapid proliferation of networks adds to the possibility of doing damage or obtaining information at multiple sites or installations.

For the purposes of this document, "hackers" are treated as outsiders. When developing protection systems for ADP systems, the potential of an insider acting as a "hacker" must also be considered.

\section{Disgruntled Employee}

The threat posed by this insider usually takes the form of destructive actions to discredit the organization or damage its resources. Since this insider has information on the organization's dependency on ADP systems, he or she is in a position to inflict considerable damage in a relatively short period of time. The perpetrator's action often takes the form of holding the resources or information hostage or withholding service to obtain redress of real or perceived injury. The perpetrator may amend or add software to cause time delayed damage to the system or information. This action is time critical in the sense that it requires that the perpetrator have time to plan and execute the necessary activities. Another action may be the theft of information or other resources for purpose of blackmail, embarrassment, or exposure to cause damage. 


\section{Financially Distressed Employee}

The threat posed by an insider in this category is directed toward those resources or quantities of information which are marketable to a second party. To attain these goals without detection, the insider requires a working knowledge of the organization and ADP system in order to complete the action. The action can either be a one-time action or an activity that continues over an extended period of time.

\section{Mentally Disturbed Employee}

The threat posed by the insider in this category can only be described as unpredictable and probably bizarre. The onset of damaging types of activity can begin gradually and accelerate over a period of time or the activity may be characterized as one dramatic outburst. Both the motive and goals of any activity are usually without logic, although they are often aimed at retribution for imagined slights or injury.

\section{Alcohol or Drug Addicted Employee/Employee with Personal Problems}

The threat posed by the alcohol or drug addicted insider is twofold. First, the person under the influence of either substance poses an immediate threat of not being in full possession of his or her faculties. The damage inflicted in this situation is not usually unintentional or accidental, although the acts can take on the characteristics of the mentally disturbed employee. Second, the addicted person is frequently under financial pressure to maintain the addiction. Under these circumstances, the person may be easily motivated to capitalize on the potential value of available resources or information.

The employee with personal problems poses a threat from two directions. First, preoccupation with the problems can lead to a failure to observe the rules and procedures which support the system security measures. Second, this individual can, in some instances, be the subject of "blackmail" efforts or can be driven to seek financial resolution of the problems through the sale of organizational resources or information.

\section{Untrained Employee}

Employees in this category are a threat to the security of a system through their failure to observe security rules and procedures or by creating system activities which result in the destruction or alteration of data. Through inadvertent acts or "innocence," information may be compromised or lost.

\section{Careless Employee}

The actions of this employee can cause a significant breakdown in the security procedures which protect system resources or information. The failures created by this situation have few limits and are unpredictable. 


\section{Outsider}

\section{Foreign Government Representative}

The goal of the persons in this category is generally to gain access to or obtain information that is stored or processed on computers. The most common method used is the exploitation of insider weaknesses. Other methods, such as wiretap, electronic eavesdropping, software or hardware tampering or modification are used; however, these methods are much more expensive and time consuming. Large databases or storage facilities are frequently targeted for these types of monitoring. Occasionally persons in this category may be motivated to destroy or interrupt systems which are vital.

\section{Extremists}

The motivation of persons in this category is most frequently aimed at destroying or disrupting activities with which he or she disagrees. The goal of persons in this category is most frequently to achieve notoriety, either personal or for a "cause".

\section{Hackers}

There are two general sub-groups in this category of threat. The first group is motivated by the challenge of breaking into a system to browse and to attempt to find other challenges or information leading to other systems. The second group, while similarly motivated, may also be seeking information or data which can be exploited or otherwise used. In either case, the threat of compromise, data loss or alteration, or denial of access to resources is equally as great. It is necessary to consider that insiders may be hackers as well.

\section{Other Acts of Man}

Threats in this category relate to those events which are the result of activities which destroy, interrupt, or alter the normal functioning of the facilities, personnel, or equipment devoted to computer processing. These events are usually associated with disrupted or destroyed utility or environmental support system. Other events relate to the dangers created by the loss of control or vicious use of noxious, toxic, flarnmable, radioactive, or explosive substances. The occurrence of these events can result in short-term or extended inability to provide normal computer processing support and may leave computing resources inaccessible for long periods of time.

\section{ENVIRONMENTAL THREATS}

\section{General}

It is necessary when addressing threats, but especially major environmental events, to examine the resources, equipment, and personnel required to restore the facility, equipment, 
and media to working order. This examination must include not only addressing major items (e.g., generator, cooling devices, and computers), but also such things as emergency power and water shutoff and operating supplies (e.g., expendable media, paper, printer supplies, etc.). In any major environmental event, barriers may be erected which might prevent area access to those key personnel whose skills are required to take protective actions or restore service (e.g., CPPM refused entry to the area containing the back-up media and documentation repository during a fire so it can be evacuated, etc.). This can pose a significant threat and should be addressed in connection with protective services. An often overlooked source of threats to computer resources and information are posed by the architectural features of a building or facility. These threats take the form of the location of such things as water mains, tunnels, passageways, windows, and inadequate walls, ceiling, and floors. These features, when interrupted, broken, or not properly secured, create potential vulnerabilities.

\section{Acts of Nature}

Threats of this category relate to those destructive natural events which can destroy, interrupt, or alter the normal functioning of the facilities, personnel, or equipment devoted to computer processing. These events are usually associated with, but not limited to, fire, wind storms, hurricanes, tornadoes, lightning, flood, earthquakes, or snow storms. The threat posed by these events must be considered in combination with the corresponding effects of the events. Some examples include fire caused by lightning, flooding caused by earthquake, water damage caused by fire fighting, or inaccessibility by personnel due to hazardous conditions. 


\section{APPENDIX B \\ ATMS USER CERTIFICATION}

\section{RESPONSIBIITIES}

The following is a listing of basic security responsibilities. All ATMS users must be knowledgeable of these responsibilities. ATMS users are required to sign this statement indicating that they understand these responsibilities before they can be authorized to access ATMS.

- Provide ACCESS CONTROL, commensurate with the sensitivity of the data processed, for hardware, software, and data (e.g., lock up or log off).

- Use computers for only AUTHORIZED JOB FUNCTIONS.

- Use AUTHORIZED SOFTWARE only.

- Have an administrative plan in place for all OFFSITE CONNECTIONS (e.g., modems) other than those provided by HLAN.

- Provide the following for SENSITTVE INFORMATTON protected BY LAW, DOE ORDERS, OR WHC POLICIES:

- PROTECT FROM UNAUTHORIZED VIEWING AND ACCESS

- LABEL with approved markings

- LOCKED PROTECTION in computer, room, desk, or cabinet

- DISPOSE of through approved methods

- REMOVE FROM STORAGE MEDIA PRIOR to a property transfer

- Have a Contingency Plan (Form A-6700-384) in place for systems which support an ESSENTIAL FUNCTION.

- Apply appropriate PASSWORD protection.

- Use only authorized BULLETIN BOARDS, PUBLIC DOMAIN SOFTWARE, FREEWARE, OR SHAREWARE.

- $\quad$ Notify the WHC CPPM (6-0237) of any SYSTEM CHANGES OR RELOCATIONS affecting the security of systems processing sensitive data.

- Notify the WHC CPPM (6-0237) of any UNUSUAL OR SUSPICIOUS EVENTS such as theft, misuse, or destruction of hardwae, software, or data. 


\section{APPENDIX B (Continued)}

\section{CERTIFICATION}

I certify that I have read the statement of ATMS User Responsibilities and understand my responsibilities for protecting the ATMS system and information.

Typed/Printed Name

Signature

Date 
APPENDIX C

\begin{tabular}{|c|c|c|}
\hline \multicolumn{3}{|c|}{ RISK ASSESSMENT FORM } \\
\hline 1. System Name & \multicolumn{2}{|c|}{ 2. Location of Equipment } \\
\hline 3. Computer Protection Program Manager & \multicolumn{2}{|c|}{ 4. Computer Protection Program Coordinator } \\
\hline Name & \multicolumn{2}{|l|}{ Name } \\
\hline Title & \multicolumn{2}{|l|}{ Title } \\
\hline Telephone Number & \multicolumn{2}{|l|}{ Telephone Number } \\
\hline \multicolumn{3}{|c|}{ 5. Identification of System: List all equipment and peripheral devices. } \\
\hline Equipment & Model \# & Serial \# \\
\hline \multicolumn{3}{|l|}{ A. } \\
\hline \multicolumn{3}{|l|}{ B. } \\
\hline \multicolumn{3}{|l|}{ C. } \\
\hline \multicolumn{3}{|l|}{ D. } \\
\hline \multicolumn{3}{|l|}{ E. } \\
\hline \multicolumn{3}{|c|}{$\begin{array}{l}\text { 6. How will the system be configured? (Check app } \\
\text { Stand Alone } \\
\square \text { Stand Alone with remote capability } \\
\text { System you will access } \\
\text { Percent of use as remote }\end{array}$} \\
\hline \multicolumn{3}{|c|}{$\begin{array}{l}\text { 7. Who is the owner of the system? } \\
\square \text { U.S. Government } \\
\square \text { Contractor (list organization) }\end{array}$} \\
\hline 8. Total Dollar Value of System & $\begin{array}{l}\text { 9. How many hours } \\
\text { per day will system be } \\
\text { used? }\end{array}$ & $\begin{array}{l}\text { 10. How many days } \\
\text { per week? }\end{array}$ \\
\hline \multicolumn{3}{|l|}{ 11. System Users } \\
\hline \multicolumn{3}{|c|}{$\begin{array}{l}\text { 12. Do the individuals in Question } 11 \text { participate in a security training program? } \\
\text { Explain Program }\end{array}$} \\
\hline
\end{tabular}




\section{Indicate the percentage of the system that is:}

Sensitive:

Non-sensitive:

14. This system is capable of storing information on the following media: (check all applicable items)
口 Floppy Disk
$\square$ Removable Hard Disk
$\square$ Other magnetic media:
$\square$ Fixed Hard Disk
口 Fixed Hard Card

15. The following threats and countermeasures apply to this system. Fill in the blank space for what you consider the risk to be (either high, medium, or low). Check the countermeasures that apply for each threat.

\begin{tabular}{|c|c|}
\hline $\begin{array}{l}\text { 9. FIRE } \\
\text { Risk } \square \text { High } \square \text { Medium } \square \text { Low } \\
\text { Countermeasures: } \\
\square \text { Sprinklers installed } \\
\square \text { Halon installed } \\
\square \text { Fire extinguishers } \\
\square \text { Fire bell available } \\
\square \text { Smoke detectors installed } \\
\square \text { Fire alarm } \\
\square \text { Fire resistant material, non combustible } \\
\square \text { Written emergency plan } \\
\square \text { Other }\end{array}$ & $\begin{array}{l}\text { b. POWER LOSS } \\
\text { Risk } \square \text { High } \square \text { Medium } \square \text { Low } \\
\text { Countermeasures: } \\
\square \text { Back-up power available } \\
\square \text { Nonvolatile memory } \\
\square \text { Auto-restart } \\
\square \text { Power surge protection exists } \\
\square \text { Other. }\end{array}$ \\
\hline $\begin{array}{l}\text { c. WATER DAMAGE } \\
\text { Risk } \square \text { High } \square \text { Medium } \square \text { Low } \\
\text { Countermeasures: } \\
\square \text { Computer location is above grade } \\
\square \text { Raised floor } \\
\square \text { Humidity recording device or indicators } \\
\text { installed } \\
\square \text { Dry pipe sprinkler } \\
\square \text { Waterproof covers for equipment } \\
\square \text { Closed metal files and cabinets } \\
\square \text { Other }\end{array}$ & $\begin{array}{l}\text { d. LOSS OF DATA INTEGRITY } \\
\text { Risk } \square \text { High } \square \text { Medium } \\
\text { Countermeasures: } \\
\square \text { Security procedures } \\
\square \text { Operating procedures (proper data entry } \\
\text { and back-up procedures) } \\
\square \text { Air conditioning } \\
\square \text { Antistatic measures (use of spray } \\
\text { chemicals, humidifiers, etc.) } \\
\square \text { Other }\end{array}$ \\
\hline $\begin{array}{l}\text { e. ELECTRIC HAZARD } \\
\text { Risk } \square \text { High } \square \text { Medium } \\
\text { Countermeasures: } \\
\square \text { Equipment is grounded } \\
\square \text { Power off controls } \\
\square \text { Fire extinguishers } \\
\square \text { Auto logging } \\
\square \text { Other. }\end{array}$ & $\begin{array}{l}\text { P. UNAUTHORIZED USE OR MISUSE } \\
\text { Risk } \square \text { High } \square \text { Medium } \\
\text { Countermeasures: } \\
\square \text { Password system established: } \\
\square \text { system access } \square \text { file access } \\
\square \text { Operating system security incorporated } \\
\square \text { Visitor logs and escort procedures } \\
\square \text { Access rosters established } \\
\square \text { InpuVloutput receipt system implemented } \\
\square \text { End-of-day checkout procedures } \\
\text { established } \\
\square \text { Other }\end{array}$ \\
\hline
\end{tabular}


APPENDIX C (Continued)

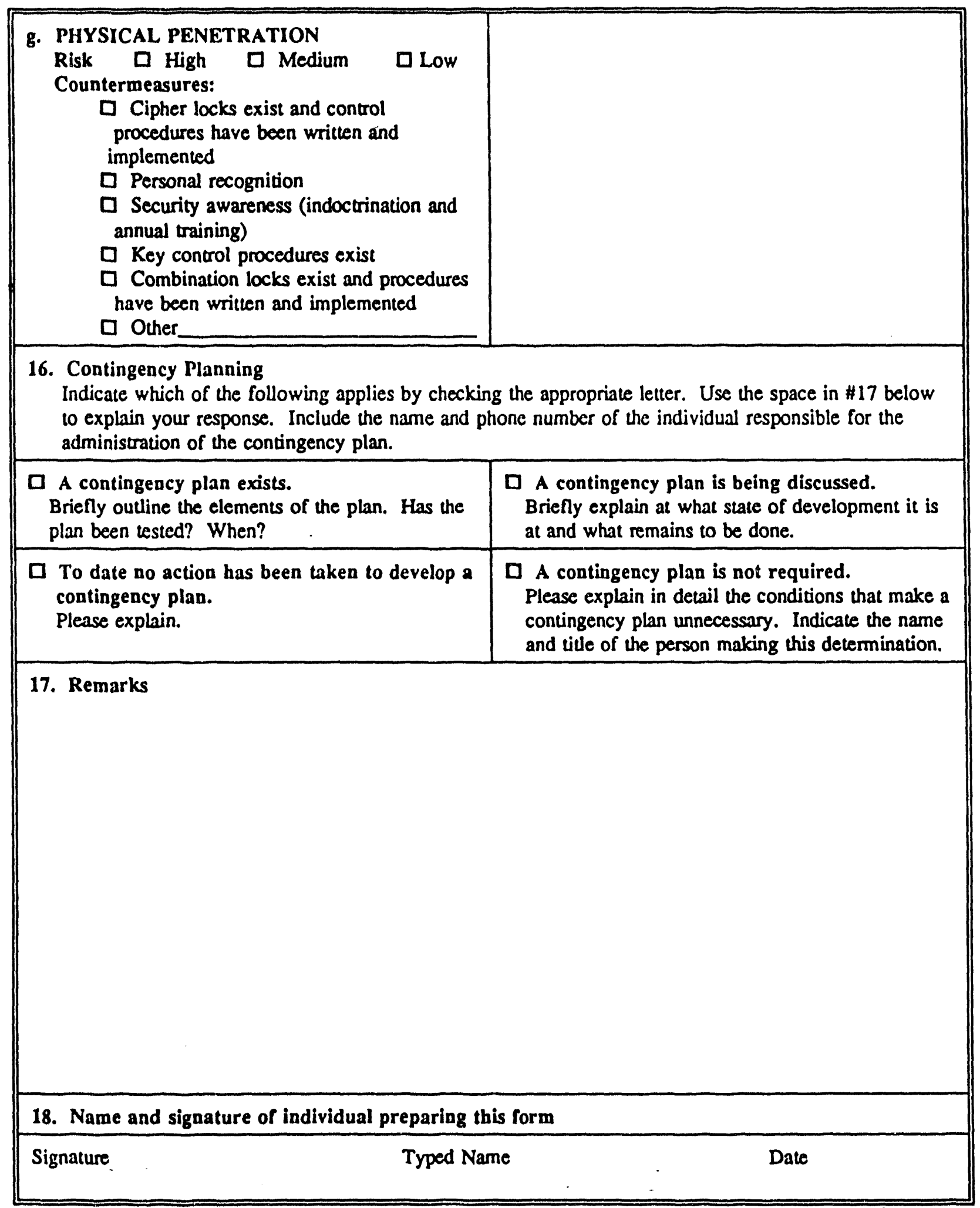




\section{APPENDDX D \\ COMPUTER SECURITY INCIDENT REPORT}

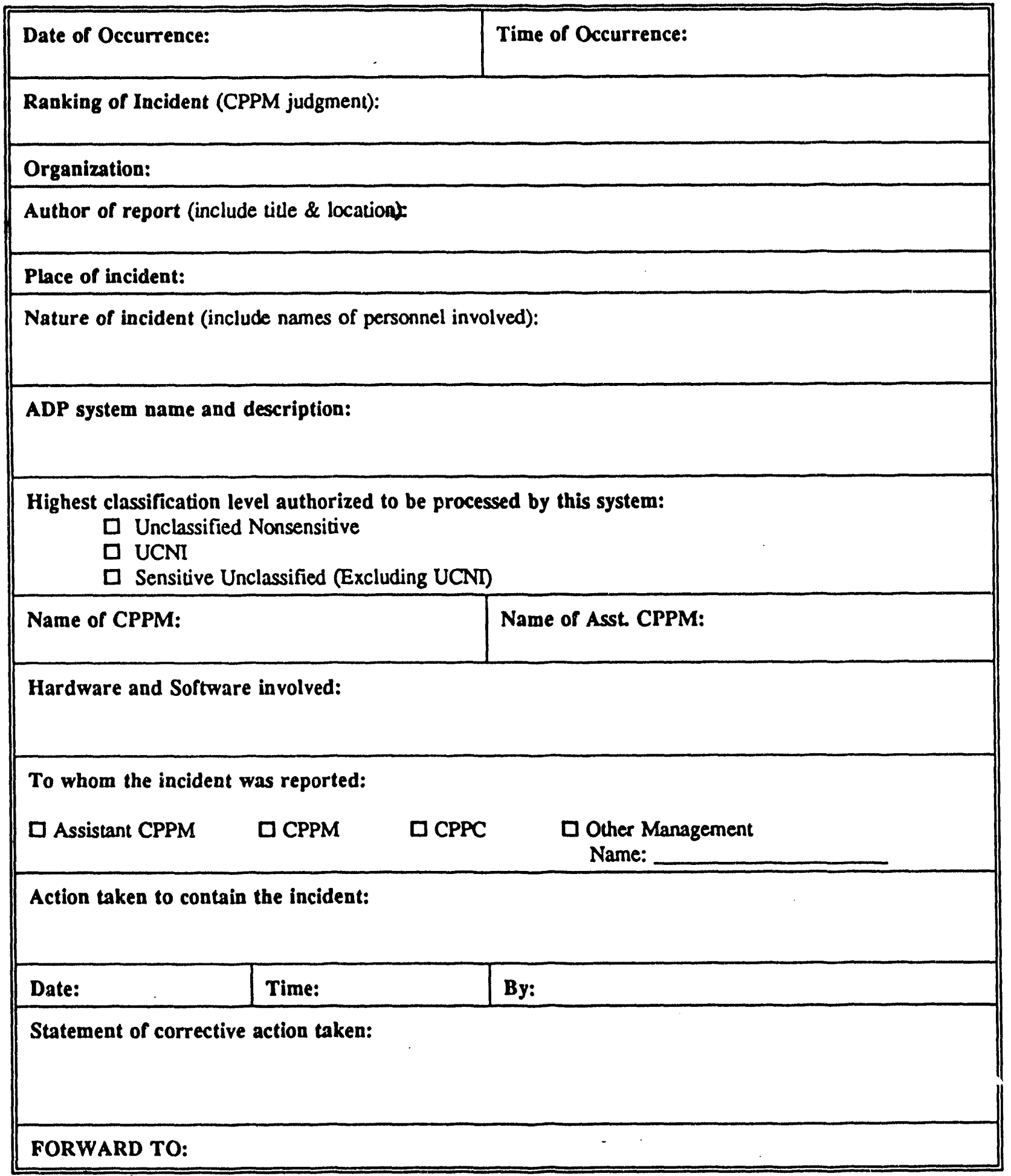

D-1 

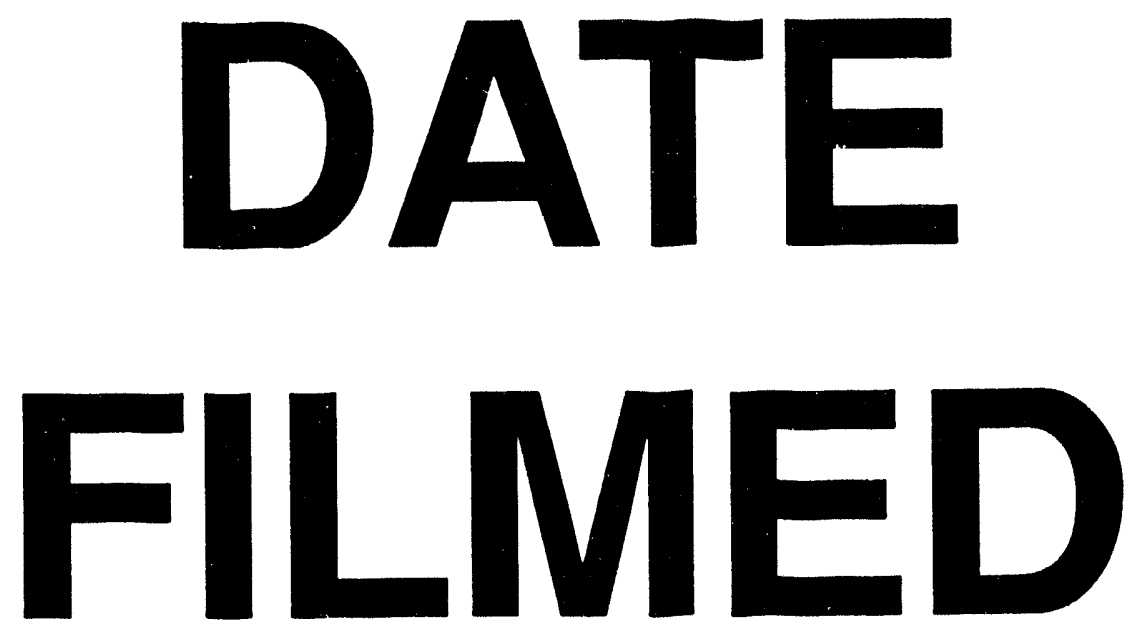

$6 / 9 / 94$
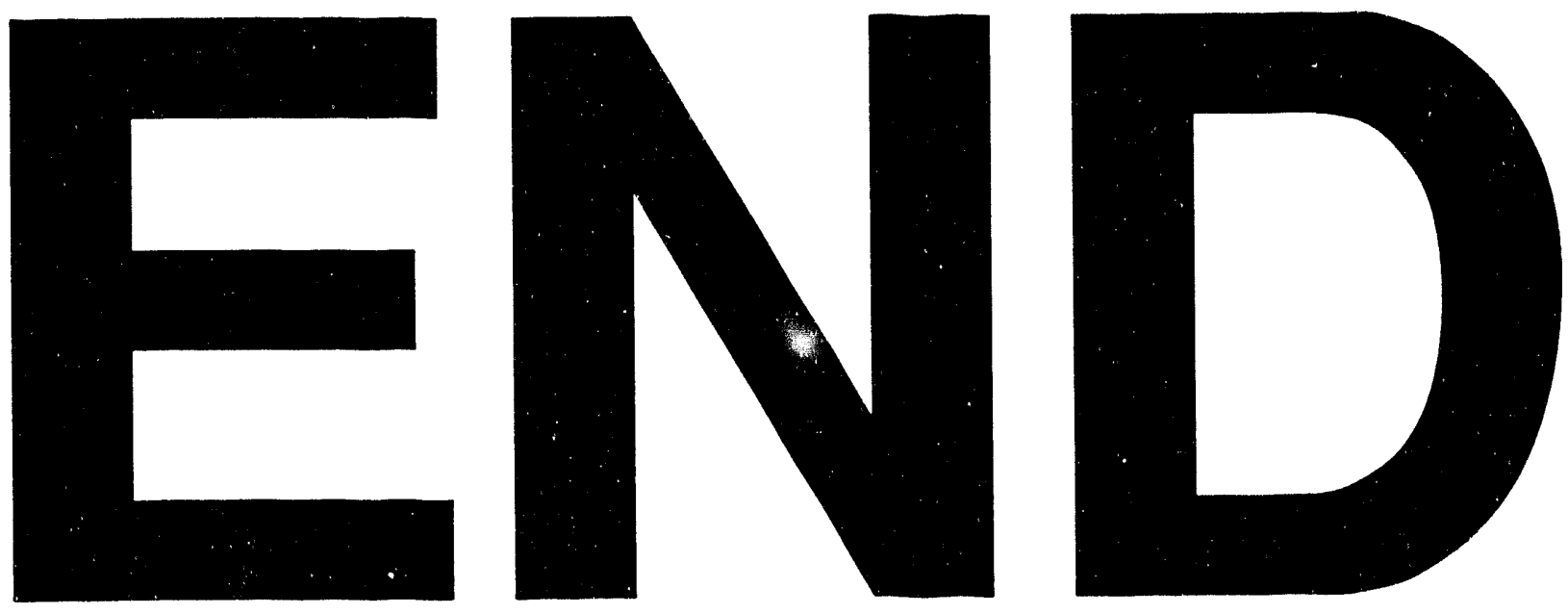